\title{
Tamsulosin in Lowering Double J Related Symptoms
}

\author{
Sudeep Raj KC, ${ }^{1}$ Bhusan Raj Timilsina, ${ }^{1}$ Gaurav Devkota, ${ }^{2}$ Rajiv Shah, ${ }^{1}$ Nirmal Lamichhane ${ }^{3}$ \\ ${ }^{1}$ Department of Urology, College of Medical Sciences-Teaching Hospital, Bharatpur, Chitwan, Nepal, ${ }^{2}$ Patan Hospital, \\ Lalitpur, Nepal, ${ }^{3}$ B.P. Koirala Memorial Cancer Hospital, Bharatpur, Chitwan, Nepal.
}

\begin{abstract}
Background: Indwelling double $\mathrm{J}$ ureteral stents are used routinely in the resolution of ureteral obstruction caused by different etiologies. Evaluation of urinary symptoms related to double-J stent indicate that these affect $73-90 \%$ of patients. Aim of this study is to evaluate the effect of tamsulosin on the DJ related complications to improve the quality of life and render symptom free life. Materials and Methods: Quasi experimental study was carried out in the department of urology in College of Medical Science, teaching hospital Chitwan, Nepal from $15^{\text {th }}$ March 2017 to $15^{\text {th }}$ March 2018. A total of 80 post operative patients were included in this study and were randomized into Group A and B with 40 patient in each group. Stent related symptoms, quality of life and IPSS (International prostate symptom score) were evaluated at the time of discharge and at the time of DJ removal. Pain was evaluated with the help of VAS at the time of discharge and at the time of DJ removal. Data were entered in MS-Excel and were imported to EZR software Version 3.4.1 for analysis. A p-value of less than 0.05 was considered significant. Results: Median age was 30.5 in Tamsulosin group and 24 years in placebo group. $(\mathrm{p}=0.68)$. At the time of discharge significant difference was noted in IPSS $(p<0.001)$, but no significant difference was noted with QoL index $(p=0.932)$ and VAS $(p=0.68)$. At the time of DJ stent removal, significant difference was noted with IPSS ( $<<0.001)$, QoL index $(p<0.001)$, VAS $(p=0.004)$ in Tamsulosin group than in Placebo group. Conclusions: Tamsulosin lowers stent related symptoms, pain and improves quality of life in patients with indwelling DJ stent.
\end{abstract}

Keywords: DJ stent; IPSS; tamsulosin; VAS.

\section{INTRODUCTION}

Historically the idea to use a stent in ureter was first described by Peck in $1926 .{ }^{1}$ It took approximately 40 years to report its clinical use which was in 1967 and later in $1970 .^{2}$ Problem that was faced was migration of the stent. ${ }^{3}$ In 1978 Finney described double $j$ stent in which there were hooks on either end to prevent migration of stent. ${ }^{4}$

Use of double $\mathrm{J}$ stent in ureter has become a routine in clinical practice in most of the endourological procedures, and in resolving ureteric obstruction of different aetiology. ${ }^{5-7}$ The stent related symptoms varies from individual to individual ranging from $19-76 \%$ and includes flank pain, suprapubic pain, frequency, urgency, incomplete voiding, dysuria, urinary incontinence and haematuria. ${ }^{8-10}$

Alpha receptors are found around smooth muscles of the ureter, trigone and bladder neck. As a foreign body DJ stent can cause discomfort through spasms in the entire length of the ureter ${ }^{11}$
Further, irritation of the trigone, may be caused by the intravesical lower coil of the stent. During the phase of voiding there will be reflux of urine which may increase pressure on the renal pelvis and cause discomfort. ${ }^{12}$ Alpha-blockers reduce symptoms like dysuria, frequency, flank pain due to stents compared to placebo. ${ }^{13}$ These symptoms are usually treated with oral analgesic such as narcotics and NSAIDs. However, these drugs are only moderately effective and don't treat the irritative bladder symptoms. ${ }^{10}$ Aim of this study is to evaluate the effect of tamsulosinas DJ related complication to improve the quality of life and rinder symptom free life.

\section{MATERIALS AND METHODS}

Quasi experimental study performed in first 80 cases in College Of Medical Science, Chitwan, Nepal, from March 2017 to March 2018 and ethical clearance was taken from institutional review community. Inclusion criteria were all the patients who underwent URSL for distal ureteric calculi and in whom DJ stenting was done. Exclusion criteria

Correspondence: Dr. Sudeep Raj KC, Department of Urology, College of Medical Sciences, Bharatpur, Nepal. Email: sudeeprkc786@gmail.com. Phone: +977-9851030974. DOI: 10.3126/jcmsn.v14i4.21634. Article received: 2018-7-29. Article accepted: 2018-12-13. 
were patients with diagnosed case of benign enlargement of prostate, over active bladder, bladder sphincter dyssynergia, any trauma to the ureter at the time of surgery, patients who needed any analgesic or any alpha blockers before the surgery other than medical expulsion therapy. Polyurethane with diameter of $6 \mathrm{~F}$; length was 24 to $26 \mathrm{~cm}$ (adult DJ) was used in this study.

Surgery was performed under general and spinal anaesthesia. After completion of surgery DJ stent was placed and X-ray KUB was done to confirm the position of the DJ stent on the next day. DJ stent was removed after 14 days of the surgery. Patients were divided into two groups, group A and group B by lottery methods. Group A received tamsulosin 0.4 mg once a day for 14 days where as group B was control group who did not receive any drugs. In both group immediate post-operative period pain management was done with ketorolac till the time of discharge. At the time of discharge on $3^{\text {rd }}$ or $4^{\text {th }}$ POD both groups were discharged with one gram of acetaminophen.

Each patient filled a written form on IPSS, at the time of discharge and on the day of stent removal; with zero being least and 35 being the maximum out of 35 score. With the help of IPSS individuals are further divided into mild (1-7), moderate (8-19) and severe symptoms (20-35). QoL is scored from $0-6$, in which zero being best goal and 6 states that patient is in the terrible condition. Visual analogue scale (VAS) ranges from one to 10 , one being the least and 10 being the maximum pain which he/she has never experienced. Data were entered in MS-Excel and were imported to EZR software Version 3.4.1 for analysis. Since all the variables compared in A and $\mathrm{B}$ groups were not normally distributed, nonparametric tests (Mann Whitney U test) were used for the analysis. A p-value of less than 0.05 was considered significant.

\section{RESULTS}

Eighty patients were included in the study with forty patients in each group. Ratio of male and female in group A was 27:13 and in group B was $24: 16$. The median age was $30.5 \mathrm{yrs}$ in group $\mathrm{A}$ and 24.0 yrs group $\mathrm{B}$, the difference in which was not significant $(p$-value $=0.53)$. IPSS at the time of discharge between A and B group was significant (p-value $<0.05$ ) with lower IPSS in group $A$ as compared to group B ( Table 1). QOL index (pvalue $=0.932)$ and VAS ( $p$-value $=0.683)$ at the time of discharge was not significant between two groups. At the time of DJ stent removal, IPSS,

\begin{tabular}{|lccc|}
\hline \multicolumn{4}{|c|}{ Table 1. Variables at the time of discharge. } \\
\hline Variables & $\begin{array}{c}\text { Tamsulosin } \\
\text { group }\end{array}$ & $\begin{array}{c}\text { Placebo } \\
\text { group }\end{array}$ & P value \\
$\begin{array}{l}\text { IPSS } \\
\text { (median) }\end{array}$ & 8 & 11 & $<0.01$ \\
$\begin{array}{l}\text { QOL } \\
\text { (Median) }\end{array}$ & 4 & 4 & 0.93 \\
$\begin{array}{l}\text { VAS } \\
\text { (Median) }\end{array}$ & 2.0 & 2.5 & 0.683 \\
\hline
\end{tabular}

QOL Index and VAS were significantly lower in group A than in group B (p-values $<0.01$ ) (Table 2 ). Hence there were significant improvements in all the parameters in the treatment group compared to the control group.

\begin{tabular}{|c|c|c|c|}
\hline Variable & $\begin{array}{l}\text { Tamsulosin } \\
\text { Group }\end{array}$ & $\begin{array}{c}\text { Placebo } \\
\text { Group }\end{array}$ & P Value \\
\hline $\begin{array}{l}\text { IPSS } \\
\text { (median) }\end{array}$ & 5 & 12 & $\begin{array}{c}7.18 \mathrm{e}-14 \\
<0.01\end{array}$ \\
\hline $\begin{array}{l}\text { QOL } \\
\text { (Median) }\end{array}$ & 1 & 4 & $\begin{array}{c}1.07 \mathrm{e}-13 \\
<0.01\end{array}$ \\
\hline $\begin{array}{l}\text { VAS } \\
\text { (Median) }\end{array}$ & 1 & 4 & $\begin{array}{c}6.16 \mathrm{e}-14 \\
<0.01\end{array}$ \\
\hline
\end{tabular}

\section{DISCUSSION}

Ureteral stent placement has been used for diversion of upper urinary tract for more than four decades $^{14}$ and has been done routinely for various urological surgeries for different indications. In the early post-operative period, stent prevents urinary obstruction due to edema of the mucosa, helps mucosal healing and dilatation of the ureter along with passage of residual stone in the long run. $^{5}$

Nevertheless, up to $76 \%$ of the patients will have symptoms associated with the presence of the stent, occasionally requiring its early removal. ${ }^{15}$ New stent designs, coatings, and biomaterials have been developed for the purpose of reducing those problems, but the ideal stent is yet to be produced. $^{16}$

Even though the exact pathophysiology of the symptoms related to the double-J stent is not known, it has been suggested that the mechanism involved could be, an increase in the pressure transmitted towards the renal pelvis during micturition and bladder irritation due to the intravesical portion of the stent. ${ }^{12}$ Both anticholinergic drugs and alpha- -adrenergic blocking agents have been used to improve symptoms related to the double-J stent with good results in the majority of cases. ${ }^{17}$

Thakur et al. in 2016 studied, total of 48 patients in which there was no difference noted at the time 
of discharge in IPSS, QoL and VAS. At the time of DJ removal there was significant difference noted in all the parameters. ${ }^{18}$ This study also showed similar results at the time of DJ removal. At the time of discharge, Thakur et al. didn't show any difference between the two groups but in this study there was significant difference noted. Use of stronger analgesic and late discharge of patient may have played a role because tamsulosin takes 48 to $72 \mathrm{hrs}$ for its action. Similarly Shelbaia in 2011 studied a total of 136 patients, and which showed a significant improvement in storage and voiding symptoms with IPSS, quality of life, physical health and pain score in tamsulosin group which was similar with this study. ${ }^{19}$ Wang et al in 2009 reported that the use of tamsulosin significantly lowers stent related symptoms and improve the quality of life in a prospective randomised study in total of 79 patients. ${ }^{20}$ Damiano in 2008 also showed similar results in study of 75 patients and demonstrated the positive effect of tamsulosin on stent related symptoms and pain after one week of treatment. ${ }^{21}$ As many studies haves how similar results with the use of tamsulosin in lowering the DJ related symptoms, pain and improve; the quality of life, it can be applied routinely in the clinical practice.

The limitations of this study are that it was not blinded, had no placebo control and there may have been a placebo effect in patients who received the active drug.

\section{CONCLUSIONS}

Tamsulosin lowers stent related symptoms, pain and improves quality of life in patients with indwelling DJ stent.

\section{Conflict of Interest}

There is no conflict of interest in this article.

\section{REFERENCES}

1. Peck CH. Tretment of obstruction of the upper ureter and early hydronephrosis. AnnSurg. 1926;1926:260-66.PMID: 17865416

2. Marmar JL.The management of the urethral obstruction with silicone rubber splint catheters. J Urol. 1970;104:731 4.doi.org/10.1016/S0022-5347(17)61744-0

3. Happerlen TW, Mardis HK, H K. Self retained internal urethral stent; A new approach. . J Urol. 1978;120:678-81.doi.org/10.1016/S0022 -5347(17)57613-2

4. Finney RP. Experience with new double J catheter stent. J Urol. 1978;120:67881.doi.org/10.1016/S0022-5347(17)57326-7

5. Chew BH, Knudsen BE, JD D. The use of stents in contemporary urology. Curr Opin Urol. 2004; 14:111-5.

6. Saltzman B. Ureteral stents. Indications, variations, and complications. Urol Clin North Am. 1988;15:481-91.PMID:3043868.

7. Denstedt JD, Wollin TA, G R. Biomaterials used in urology: current issues of biocompatibility, infection, and encrustation. J Endourol. 1998;12(493-500).doi.org/10.1089/ end.1998.12.49.

8. Vega Vega A, García Alonso D, CJ GA. Characterization of urinary tract symptoms and quality of life in patients with double-pig-tailed ureteral stents. Actas Urol Esp. 2007;31:73842.DOI: 10.1016/S0210-4806(07)73714-2.

9. Miyaoka R, Monga M. Ureteral stent discomfort: Etiology and management. Indian $\mathrm{J}$ Urol. 2009;25:455-60.DOI:
[10.4103/0970-
1591.57910].

10. Dellis A, Joshi HB, Timoney AG, Jr KF. Relief of stent related symptoms: review of engineering and pharmacological solutions. J Urol. 2010;184:1267-72doi.org/10.1016/ j.juro.2010.06.043.

11. Kwon J K, Cho KS, Oh CK, Kang DH, Lee $\mathrm{H}$, WS H. The beneficial effect of alphablockers for ureteral stent-related discomfort: systematic review and network meta-analysis for alfuzosin versus tamsulosin versus placebo. BMC Urology. 2015;15:1-10.doi.org/10.1186/s12894-0150050-5.

12. Thomas R. Indwelling ureteral stents: impact of material and shape on patient comfort. J Endourol. 1993;7(2):13740.doi.org/10.1089/end.1993.7.137.

13. Joshi HB, Stainthorpe A, MacDonagh RP, Keeley FX Jr, Timoney AG, MJ B. Indwelling ureteral stents: evaluation of symptoms, quality of life and utility. J U r o 1. $2003 ; 169: 1065$ 9.doi.org/10.1097/01.ju.0000048980.33855 .90 .

14. Zimskind PD, Fetter TR, JL W. Clinical use of longterm indwelling silicone rubber ureteral splints inserted cystoscopically. J Urol. 1976;97:840-4.PMID:6025928.

15. Joshi HB OA, Newns N, Keeley FX Jr, Timoney AG. Characterization of urinary symptoms in patients with ureteral stents. Urology. 2002;59:511-6.doi.org/10.1016/ S0090-4295(01)01644-2. 
16. Lange $\mathrm{D}, \mathrm{BH} \mathrm{C}$. Update on ureteral stent technology. Ther Adv Urol. 2009;1:1438.doi.org/10.1177/1756287209341306.

17. Lim KT, Kim YT, Lee TY, SY P. Effects of tamsulosin, solifenacin, and combination therapy for the treatment of ureteral stent related discomforts. Korean J Urol. 2011;52:4858.doi.org/10.4111/kju.2011.52.7.485.

18. Thakur DK, Chapagain S, Luitel B, Chalise PR, Sharma UK, PR G. Efficacy of Tamsulosin in Relieving Double-J Stentrelated Symptoms: a Randomized Controlled Study. JSSN. 2016;19:36.DOI: http://dx.doi.org/10.3126/jssn.v18i3.15301.

19. Shelbaia A, Elnashar A. Role of Tamsulosin in Improving Double-J Ureteric Stent-Related
Symptoms. African Journal of Urology. 2011;17(4):111-4.DOI: [10.2147/ DDDT.S103195].

20. Wang CJ, Huang SW, CH C. Effects of specific $\alpha-1 \mathrm{~A} / 1 \mathrm{D}$ blocker on lower urinary tract symptoms due to double-J stent: a prospectively randomized study. . Urol Res. 2009;37:147-52.DOI: $10.1007 / \mathrm{s} 00240$ -009-0182-8.

21. Damiano R, Autorino R, M DS. Effect of tamsulosin in preventing ureteral stentrelated morbidity: a prospective study. J Endourol. 2008;22:651-6.DOI: 10.1089/ end.2007.0257.

Citation: KC SR, Timilsina BR, Devkota G, Shah R, Lamichanne N. Tamsulosin In Lowering Double J Related Symptoms. JCMS Nepal. 2018;14(4):196-9. 